\title{
Why women bleed and how they are saved: a cross-sectional study of caesarean section near-miss morbidity
}

\author{
S. Maswime ${ }^{1 *}$ (D) and E. J. Buchmann ${ }^{2}$
}

\begin{abstract}
Background: Maternal deaths from 'bleeding during and after caesarean section' (BDACS) have increased in South Africa, and have now become the largest sub-cause of deaths from obstetric haemorrhage. The aim of this study was to describe risk factors and causes of near-miss related to BDACS and interventions used to arrest haemorrhage and treat its effects.

Methods: Cross-sectional prospective study in 13 urban public hospitals in South Africa, from July to December 2014.

Results: There were 93 cases of near-miss related and 7 maternal deaths related to BDACS. The near-miss rate was 2.1/ 1000 live births, and the case fatality rate was 3.5/10 000 caesarean sections. Associated near-miss risk factors were previous caesarean section in $60 \%$ of multiparas, pre-operative anaemia (55\%), abruptio placentae (20\%) and placenta praevia and/or accreta (20\%). Atonic uterus (43\%) was the most frequent anatomical cause of bleeding for near-miss, followed by surgical trauma (29\%). The median duration of the operations resulting in near-miss was 90 min, with $81 \%$ noted as difficult by the surgeon. Interventions in cases of near-miss included second-look laparotomy $(46 \%)$, hysterectomy (41\%), B-Lynch brace suture (9\%), intensive care unit admission (32\%) and red cell transfusion $\geq 3$ units (21\%).

Conclusion: Cases from maternal near-miss from BDACS were frequently associated with pre-operative risk factors. Extensive life-saving interventions were required during and after the operations. An important factor in initiating the sequence of interventions is the realisation by the surgeon that the caesarean section is difficult, so that the progression from uneventful operation to near-miss to death can be arrested.
\end{abstract}

Keywords: Near-miss, Caesarean section related haemorrhage, Bleeding during and after caesarean section

\section{Background}

The safety of caesarean sections has recently come into question in South Africa. Maternal death resulting from 'bleeding during and after caesarean section' (BDACS) is becoming increasingly frequent. The triennial reports of the government's confidential enquiries into maternal deaths recorded 78 such deaths in 2002-2004, 140 in 2005-2007, 180 in 2008-2010, and 221 in 2011-2013 [14]. Maternal death from BDACS is now the largest subcause of death from obstetric haemorrhage in South Africa [4]. The increase in maternal deaths has been attributed to

\footnotetext{
* Correspondence: Tumishang.Maswime@wits.ac.za

${ }^{1}$ Wits Obstetrics and Gynaecology Clinical Research Division, Johanesburg, South Africa

Full list of author information is available at the end of the article
}

a rising national caesarean section rate, but this increase exceeded the rise in caesarean section rate, which increased from $12.7 \%$ in $2001 / 02$ to $20.8 \%$ in $2012 / 13$ [5]. Other possible reasons, for which data are lacking, related to changes in health care quality, such as a lower standard of surgical skill with increased risk of bleeding [6], failure to detect antepartum risk factors, and possibly substandard labour management, anaesthesia and post-operative care.

Globally, there are insufficient data on maternal deaths related to BDACS, especially in terms of clinical and surgical detail. Even with the recent increase in deaths, these events are so rare that meaningful prospective studies are difficult to do. A helpful alternative is to study 'near-miss' related to BDACS. A maternal nearmiss is a woman who survives severe complications 
during pregnancy, childbirth or postpartum. The study of near-miss is an increasingly useful tool in obstetric clinical audit, because of the larger number of cases available for study compared with maternal deaths, and because valuable information can be obtained on how clinical and surgical and clinical management obstacles are overcome after the onset of an acute complication [7].

To our knowledge, there has been no published scientific work focusing on maternal near-miss related to BDACS. Studies or audits on near-miss could improve understanding of the evolution of severe bleeding at caesarean section, and describe opportunities taken and missed to control the bleeding and treat its consequences. The information gained may inform quality improvement and interventions to reduce near-miss and death from BDACS.

The aim of this study was to determine the risk factors and causes of near-miss related to BDACS and to describe the clinical and surgical interventions undertaken.

\section{Methods}

This was a cross-sectional prospective study in 13 government hospitals in southern Gauteng province, South Africa, from July to December 2014. Ethical approval was obtained to conduct this study from the University of the Witwatersrand's Human Research Ethics Committee. Informed written consent was obtained from the participants.

The city of Johannesburg is the geographic and economic centre of southern Gauteng province. There are 18 government hospitals with maternity services in southern Gauteng, with about 100000 births per annum. Three of these hospitals are university-attached tertiary referral hospitals. The 13 hospitals in the study included the three tertiary hospitals, as well as seven regional referral hospitals, and three district hospitals. The district hospitals are staffed by non-specialist doctors and have relatively small case loads. The regional hospitals all have at least one specialist, as well as medical officers who are responsible for most of the daily clinical activities. The tertiary hospitals are better resourced in terms of equipment and facilities, and include university faculty staff and residents training to become specialists.

The World Health Organization (WHO) Intervention criteria were used to identify cases of near-miss, and were modified to suit this population [7]. Only nearmisses related to BDACS were included in this study. A near-miss related to BDACS was any woman with a gestational age $\geq 24$ weeks, or who delivered a baby weighing $\geq 500 \mathrm{~g}$, who had a caesarean section with a combined intraoperative and postoperative blood loss $\geq 1000 \mathrm{~mL}$, and at least one of the following: red cell blood transfusion $\geq 3$ units, emergency hysterectomy, repeat laparotomy, transfer to a higher level of care, started or restarted postoperative ventilation, use of inotropic drugs, acute dialysis, cardiopulmonary resuscitation and admission to an intensive care unit. Women with ruptured uterus, extra-uterine pregnancy, and where another cause of haemorrhage was the primary reason for bleeding, were excluded.

The researcher trained obstetric staff in each hospital on how to identify a near-miss from BDACS. Each time such a case was identified, a staff member notified the researcher telephonically. The researcher then travelled to the hospital and screened the file for study eligibility. Data were collected from maternal case records, and supplemented, where necessary, from patients themselves or from staff. Informed consent was obtained from the patients. Data collected from the clinical notes were antenatal history, details about the previous pregnancy and blood test results, reason for admission, clinical management, and events leading to the decision for caesarean section. Details about the caesarean section, the findings and the complications were recorded, as well as postnatal observations and interventions. The researcher made regular visits to all hospitals to ensure ongoing surveillance. Numbers of maternal deaths related to BDACS were also recorded.

A sample of 100 near-misses related to BDACS was envisaged to provide reasonable confidence intervals for observed percentage frequencies. With a sample of 100 subjects, an observed percentage has $95 \%$ confidence limits that are not more than $10 \%$ above and below it. Data analysis employed quantitative techniques, using Stata version 11 software (Statacorp, College Station, TX, USA). Descriptive data were analysed using medians, ranges and interquartile ranges for continuous variables, and proportions with percentages for categorical variables. Comparisons of categorical variable frequencies were made using Fisher's exact test. A $p$-value $<0.05$ was used to determine statistical significance.

\section{Results}

The hospitals reported 93 near-misses related to BDACS, as well as 7 maternal deaths. The total number of deliveries at all the hospitals was 46775 , of which 20527 were caesarean sections (43\%). The near-miss related to BDACS rate was therefore 2.1 per 1000 (93/ 43474) live births, and the BDACS- related case fatality rate was 3.4 per 10000 caesarean sections.

Obstetric data and risk factors for near-misses are shown in Table 1 . Teen pregnancy $(n=2)$ and parity $\geq 4$ $(n=5)$ were infrequent. Twenty women were nulliparous and 73 were multiparous. Forty-four (60.3\%) of the multiparous women had previous caesarean sections. Anaemia prior to caesarean section (haemoglobin level $<11.0 \mathrm{~g} / \mathrm{dL}$ ) was found in 49 of 89 women tested $(55.1 \%)$. Thirty-six women (40.4\%) were HIV 
Table 1 Obstetric characteristics and risk factors for maternal near-miss from bleeding during or after caesarean section ( $n=93$, unless otherwise specified because of missing data)

\begin{tabular}{|c|c|c|}
\hline & Number & Percent \\
\hline \multicolumn{3}{|l|}{ Maternal age (years): } \\
\hline$<20$ & 2 & 2.2 \\
\hline $20-34$ & 69 & 74.2 \\
\hline$\geq 35$ & 22 & 23.7 \\
\hline \multicolumn{3}{|l|}{ Parity: } \\
\hline 0 & 20 & 21.5 \\
\hline $1-3$ & 68 & 73.1 \\
\hline 4 & 5 & 5.4 \\
\hline Attended antenatal clinic & 83 & 89.2 \\
\hline Previous caesarean section & 44 & 47.3 \\
\hline \multicolumn{3}{|c|}{ Haemoglobin level prior to caesarean section $(\mathrm{g} / \mathrm{dL})(n=89)$ : } \\
\hline$<8.0$ & 11 & 12.4 \\
\hline $8.0-10.9$ & 38 & 42.7 \\
\hline$\geq 11.0$ & 40 & 43.0 \\
\hline HIV infection $(n=89)$ & 36 & 40.4 \\
\hline Antenatal weight $\geq 90 \mathrm{~kg}(n=79)$ & 8 & 10.1 \\
\hline \multicolumn{3}{|l|}{ Caesarean section $(n=91)$ : } \\
\hline Elective (planned) & 11 & 12.1 \\
\hline Emergency not in labour & 28 & 30.8 \\
\hline Emergency in first stage & 44 & 48.4 \\
\hline Emergency in second stage & 8 & 8.8 \\
\hline Hypertensive disorder of pregnancy & 26 & 28.0 \\
\hline Abruptio placentae & 19 & 20.4 \\
\hline \multicolumn{3}{|l|}{ Placenta praevia/accreta: } \\
\hline Placenta praevia & 7 & 7.5 \\
\hline Placenta accreta & 9 & 9.7 \\
\hline Placenta praevia and accreta & 3 & 3.2 \\
\hline \multicolumn{3}{|l|}{ Birth weight $(\mathrm{g})(n=85)$ : } \\
\hline$<1000$ & 6 & 7.1 \\
\hline $1000-2499$ & 33 & 38.8 \\
\hline$\geq 2500$ & 46 & 54.1 \\
\hline
\end{tabular}

infected. Clinical risk factors included hypertensive disorders in pregnancy in $26(28.0 \%)$, abruptio placentae in $19(20.4 \%)$, and placenta praevia and/or accreta in 19 women (20.4\%) Nine of the 19 women with abruptio placentae had a hypertensive disorder. The main primary indications for caesarean section were fetal distress $(n=14 ; 15.1 \%)$, abruptio placentae $(n=13 ; 14.0 \%)$ and placenta praevia $(n=12 ; 12.9 \%)$. Eleven women had caesarean section for prolonged labour, 7 in the first stage of labour (7.5\%) and 4 in the second stage $(4.3 \%)$. Twenty-four infants were stillborn, 17 of them in association with abruptio placentae. The surgeons who started the caesarean sections were non-specialists in 29 cases (31.2\%), residents in 54 cases (58.1\%) and specialists in 7 cases $(7.5 \%)$. Seven caesarean sections $(7.5 \%)$ were done in district hospitals, $22(23.7 \%)$ in regional hospitals and 64 (68.9\%) in tertiary hospitals.

The most frequent cause (anatomical site) of haemorrhage was atonic uterus $(n=40 ; 43.0 \%)$, followed by uterine incisional bleeding $(n=27 ; 29.0 \%)$, placental site bleeding $(n=16 ; 17.2 \%)$, bleeding at the bladder reflection $(n=8 ; 8.6 \%)$, pampiniform venous plexus bleeding $(n=5 ; 5.4 \%)$ and abdominal wall bleeding $(n=4 ; 4.3 \%)$. Two or more causes of bleeding occurred in some women. In 14 women (15.1\%), the cause of haemorrhage was not specified. The causes of bleeding were compared between women with previous caesarean section, placenta praevia/accreta, abruptio placentae, and the remainder (considered as having no surgical risk). There were significant associations between placenta praevia/ accreta and placental site bleeding $(p<0.01)$, and between abruptio placentae and atonic uterus $(p=0.04)$. There was a trend to more frequent pampiniform plexus and abdominal wall bleeding in women with previous caesarean section (Table 2).

The surgeons noted difficulty in 76 operations (81.7\%). The duration of surgery was estimable in 80 cases, and was $<60 \mathrm{~min}$ in 14 (17.5\%), $60-119 \mathrm{~min}$ in $34(42.5 \%)$ and $\geq 120 \mathrm{~min}$ in $32(40.0 \%)$. The median duration was $90 \mathrm{~min}$, with a range of $23-345 \mathrm{~min}$. Forty-nine women (52.7\%) received blood transfusions during their caesarean sections. Medications and procedures used to arrest bleeding (in addition to routine intravenous oxytocin) included ergometrine, misoprostol, prostaglandin F2alpha, tranexamic acid, B-Lynch brace suture, systematic uterine vessel ligation (devascularisation), and intrauterine balloons (Table 3). The median blood loss at caesarean section (estimated by the surgeons in 69 cases) was $1000 \mathrm{~mL}$, with a range of $250-3600 \mathrm{~mL}$. Second-look emergency laparotomy was performed in 43 women, of whom 18 underwent hysterectomy (total hysterectomies: $n=38 ; 40.9 \%)$ and 8 had B-Lynch compression sutures (of which 4 failed, requiring hysterectomy). Fourteen women had only resuturing or uterine vessel ligation done, and 5 required no specific haemostatic procedure. Seventy-four women (79.6\%) received three or more units of red cell transfusion during their hospital stay. The median lowest postoperative haemoglobin level was $6.05 \mathrm{~g} / \mathrm{dL}(n=90)$, with a range of $2.8-12.5 \mathrm{~g} / \mathrm{dL}$. Thirty-six of 78 women in whom the platelet count was measured had a postoperative thrombocytopenia $<100000 / \mu \mathrm{L}$. Seven women had severe acute kidney injury (serum creatinine $\geq 250 \mu \mathrm{mol} / \mathrm{L}$ ), and 6 required dialysis. Thirty women (32.3\%) were admitted to intensive care units postoperatively. Eleven women (11.8\%) 
Table 2 Caesarean section near-miss haemorrhage anatomical sites, according to presence or absence of specific prior surgical risk factors

\begin{tabular}{lllll}
\hline & $\begin{array}{l}\text { Previous caesarean } \\
\text { section only }(n=23)\end{array}$ & $\begin{array}{l}\text { Placenta praevia/accreta }(n=19)- \\
\text { includes 13 previous caesarean sections }\end{array}$ & $\begin{array}{l}\text { Abruptio placentae }(n=19) \text { - includes } \\
8 \text { previous caesarean sections }\end{array}$ & $\begin{array}{l}\text { No surgical risks } \\
\text { anticipated }(n=32)\end{array}$ \\
\hline Uterine incision & 5 & 5 & 3 & 14 \\
Atonic uterus & 9 & 4 & $14^{*}$ & 13 \\
Placental site & 1 & $14^{*}$ & 0 & 1 \\
Bladder reflection & 1 & 3 & 2 & 2 \\
Pampiniform plexus & 3 & 0 & 1 & 1 \\
Abdominal wall & 3 & 1 & 0 & 0 \\
Not specified & 3 & 1 & 2 & 8 \\
\hline
\end{tabular}

*Comparison for placental site bleeding, placenta praevia/accreta v. no surgical risks: $p<0.01$

*Comparison for atonic uterus, abruptio placentae v. no surgical risks: $p=0.04$

received inotropic drugs. Ten women (10.8\%) were transferred by ambulance to higher levels of care.

The seven maternal deaths included a case of placenta accreta with previous caesarean section, who required a hysterectomy, and one woman with placental abruption who died four days postoperatively from multi-organ dysfunction. The remaining five women had no surgical risk factors, and all had intraoperative blood loss $\leq 700 \mathrm{~mL}$.

\section{Discussion}

This study, from a middle-income urban setting, found that about one in 216 caesarean sections are complicated by severe morbidity from bleeding, and that about 1 in 14 women with severe morbidity progress to maternal death. The near-miss definition seemed appropriate as applied in this study, providing a sample of women

Table 3 Intraoperative interventions during caesarean section in cases of near-miss haemorrhage $(n=93$ unless otherwise specified because of missing data). Multiple interventions were used in some cases

\begin{tabular}{lll}
\hline & Number & Percent \\
\hline Red cell blood transfusion $(n=89)$ & 40 & \\
$\quad$ None & 8 & 44.9 \\
1 unit & 22 & 24.0 \\
2 unit & 19 & 21.3 \\
$\geq 3$ units & 19 & 20.4 \\
Intramuscular or intravenous ergometrine & 8 & 8.6 \\
Oral or rectal misoprostol & 10 & 10.8 \\
Intramyometrial prostaglandin-F2-alpha & 6 & 6.5 \\
Intravenous tranexamic acid & 7 & 7.5 \\
Systematic uterine vessel ligation (devascularisation) & 7 & 4.3 \\
Intrauterine balloon $^{\text {a }}$ & 4 & 16.1 \\
B-Lynch compression suture $^{\text {a }}$ & 15 & 21.5 \\
Hysterectomy
\end{tabular}

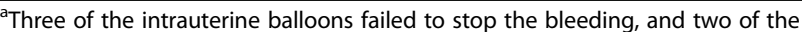
B-Lynch compression sutures (in whom balloons were not used) failed. All five failures went on to hysterectomy severely affected by bleeding, evidenced by a very low median postoperative haemoglobin level of $6.05 \mathrm{~g} / \mathrm{dL}$.

The most important common risk factors for nearmiss related to BDACS were preoperative anaemia (over half had haemoglobin $<11.0 \mathrm{~g} / \mathrm{dL}$ ), and previous caesarean section (in over half of multiparas). A rising caesarean section rate increases not only the number of caesarean sections currently, but adds women with previous caesarean section to those who will become pregnant in future. This is one of the reasons for calls to prevent the first caesarean section in women [8]. The HIV infection rate, while high, is not statistically significantly higher than the $28.7 \%$ prevalence in pregnant women in this part of South Africa $(p=0.05)$ [9]. Anaemia limits the body's response to blood loss, and makes any caesarean section potentially hazardous. Previous caesarean section is well known as a cause of overall surgical difficulty [10]. Accordingly, multiple causes of bleeding were found in women with previous caesarean sections, including extrauterine causes such as pampiniform plexus and abdominal wall injury. The other two important risk factor categories, abruptio placentae and placenta previa/accreta, are uncommon conditions, yet occurred in large numbers in this series. The published literature supports our finding of uterine atony being the most common cause of post-partum haemorrhage, and placental site bleeding associated with placenta praevia/accreta [11]. Previous caesarean section itself is also associated with placenta praevia/accreta [12]. A number of women had no specific surgical risk factors, and bled severely from a variety of sources. The absence of risk factors gives no guarantee of an uncomplicated caesarean section and postoperative course.

In $76 \%$ of near-misses related to BDACS, the caesarean sections were noted by the surgeons as difficult, and early interventions were made intra-operatively. A range of life-saving options was used, usually in combination, to manage the source and effects of bleeding. Medical management included utero-tonics, tranexamic acid, 
inotropic support and blood transfusion, with recourse to emergency transport if needed, and intensive care, suggesting the elements of a well-resourced functional health service. Surgical options included frequent use of uterine vessel ligation, B-Lynch compression sutures and hysterectomy, both at caesarean section and at secondlook emergency laparotomy, suggesting the presence of skilled obstetric surgeons. The few attempts at intrauterine balloon tamponade were mostly unsuccessful, but this may reflect the characteristics of this group of women. Balloon tamponade works best when placed early in severe postpartum haemorrhage after vaginal birth [13].

This study has certain strengths and limitations. Strengths were a robust near-miss definition and a sample size that allowed description of prevalence and relationships. Another strength is the clinical detail obtained from inspection of all women's clinical notes by a specialist obstetrician. The reliance on record review for clinical information is also a limitation, with some data missing. Limitations include the possibility that some near-miss cases were not included, because the researcher and the trained contacts at the hospitals could not be in attendance at all births. However, it is certain that all maternal deaths from BDACS were included, because these are subject to compulsory confidential enquiries.

Further research should focus on detail in risk factors, surgical findings and interventions. An ideal design would be a case-control study, in which near-miss cases are compared with non-near-miss caesarean sections for risk factors, surgical findings and interventions. A similar study should also be done in a resource-poor setting, where access to technological and specialist interventions is restricted, and where there are likely to be more maternal deaths.

\section{Conclusion}

Our findings show that maternal near-miss from BDACS is uncommon, but severe enough to necessitate extensive life-saving interventions. These require skilled or specialist health professionals, and a functional obstetric service with access to medication, blood transfusion, emergency transport and intensive care units. An important factor in initiating the sequence of interventions is the realisation by the surgeon that the caesarean section is difficult, so that the progression from uneventful operation to near-miss to death can be arrested.

\section{Abbreviations}

BDACS: Bleeding during and after caesarean section; g: Gram; g/dl: Gram/ decilitre; HIV: Human immunodeficiency virus; $\mathrm{mL}$ : Millilitre; $\mathrm{n}$ : Number; p: Probability; v.: Versus; WHO: World Health Organization
Funding

- Carnegie Corporation of New York, Grant B8749.R01.

- Research submitted in this report was supported by the South African Medical Research Council under a Self-Initiated Research Grant.

The work as supported by the Carnegie Corporation of New York, and the, SA MRC, the views and opinions expressed, however, are not those of the Carnegie Corporation or the SA MRC, but of the authors.

\section{Availability of data and materials}

Data will be available from the corresponding author.

\section{Authors' contributions}

SM: Made substantial contributions to conception and design, acquisition of data, and interpretation of data; Was involved in drafting the manuscript, revising it critically for important intellectually content; Acquired funding for the study. EB: Made substantial contributions to conception and design, and analysis and interpretation of data; Supervised the study. SM and EB: Gave final approval of the version to be published; Agreed to be accountable for all aspects of the work in ensuring that questions related to the accuracy or integrity of any part of the work are appropriately investigated and resolved.

\section{Authors' information}

Not applicable.

\section{Competing interests}

This study was done as part of a PhD with the University of the Witwatersrand. Funding to do a full-time PhD was received from the Carnegie Corporation of New York. Funding for the research was received from the Carnegie Corporation of New York and the South African Medical Research Council.

Consent for publication

Not applicable.

Ethics approval and consent to participate

Ethics approval granted by the University of the Witwatersrand Human Ethics Research Committee. Clearance certificate: M140137. All the nearmisses gave written consent to participate in the study, consent was not required for the maternal deaths.

\section{Author details}

'Wits Obstetrics and Gynaecology Clinical Research Division, Johanesburg, South Africa. ${ }^{2}$ Department of Obstetrics and Gynaecology, University of the Witwatersrand, Johannesburg, South Africa.

Received: 4 February 2016 Accepted: 6 December 2016 Published online: 09 January 2017

\section{References}

1. Department of health. Saving Mothers 2002-2004: Third report on the confidential enquiries into maternal deaths in South Africa. Pretoria: Department of Health; 2006.

2. Department of health Department of health. Saving Mothers 2005-2007: Fourth report on the confidential enquiries into maternal deaths in South Africa. Pretoria: Department of Health; 2009.

3. Department of health. Saving Mothers 2008-2010: Fifth report on the confidential enquiries into maternal deaths in South Africa. Pretoria: Department of Health; 2011.

4. Department of health. Saving Mothers 2011-2013: Sixth report on the confidential enquiries into maternal deaths in South Africa. Pretoria: Department of Health; 2015.

5. Massyn N, Day C, Dombo M, et al. District health Barometer 2012/13. Durban: Health Systems Trust; 2013.

6. Gebhart G, Fawcus S, Moodley X, et al. Maternal death and caesarean section in South Africa: Results from 2011 to 2013 Saving mothers report of the national committee for confidential enquiries into maternal deaths. $\mathrm{S}$ Afr Med J. 2015;105(4):287-91.

7. Say L, Souza J, Pattinson R. Maternal near miss - towards a standard tool for monitoring quality of maternal health care. Best Pract Res Clin Obstet Gynaecol. 2009;23:287-96. 
8. Spong C, Berghella V, Wenstrom K, Mercer B, Saade G. Preventing the first cesarean delivery. Obstet Gynecol. 2012;120:1181-93.

9. Deirdre J, Lyell M. Adhesions and perioperative complications of repeat cesarean delivery. Am J Obstet Gynecol. 2011;205(6 Suppl):S12-7.

10. Avert. South Africa HIV and statistics. http://www.avert.org/south-africa-hivaids-statistics.htm. Accessed 7 Oct 2015.

11. Walfish M, Neuman A, Wlody D. Maternal haemorrhage. Br J Anaesth. 2009; 103(suppl 1):i47-56.

12. De Souza R. Caesarean section on maternal request for non-medical reasons: putting the UK national institute of health and clinical excellence guidelines in perspective. Best Prac Res Clin Obstet Gynaecol. 2013;27:165-77.

13. Bakri $Y$, Arulkumaran S. Intrauterine balloon tamponade for control of postpartum hemorrhage. UpToDate, Post TW (Ed), UpToDate, Waltham, MA; 2015. https://www.uptodate.com/contents/intrauterine-balloon-tamponadefor-control-of-postpartum-hemorrhage. Accessed 12 Dec 2016.

Submit your next manuscript to BioMed Central and we will help you at every step:

- We accept pre-submission inquiries

- Our selector tool helps you to find the most relevant journal

- We provide round the clock customer support

- Convenient online submission

- Thorough peer review

- Inclusion in PubMed and all major indexing services

- Maximum visibility for your research

Submit your manuscript at www.biomedcentral.com/submit
Biomed Central 